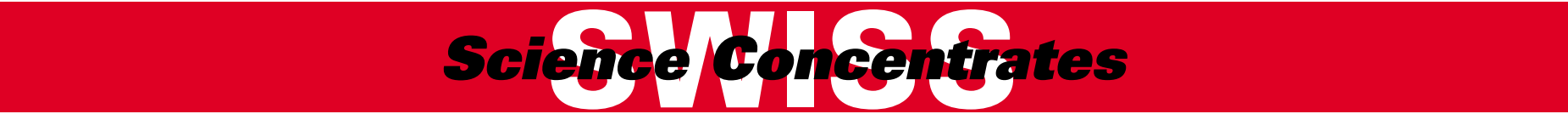

\section{Absolute Configuration of Chirally Deuterated Neopentane}

J. Haesler*, I. Schindelholz, E. Riguet, C. G. Bochet, and W. Hug* Nature (London, UK) 2007, 446, 526

University of Fribourg

In this article, the synthesis of $(R)-\left[{ }^{2} \mathrm{H}_{1},{ }^{2} \mathrm{H}_{2},{ }^{2} \mathrm{H}_{3}\right]$-neopentane, a molecule chiral as a result of dissymmetric mass distribution only, is presented. The unequivocal determination of the absolute configuration of this pure, $T_{d}$ symmetric hydrocarbon molecule was possible only by combining instrumental advances in Raman Optical Activity (ROA) and quantum chemical computations.

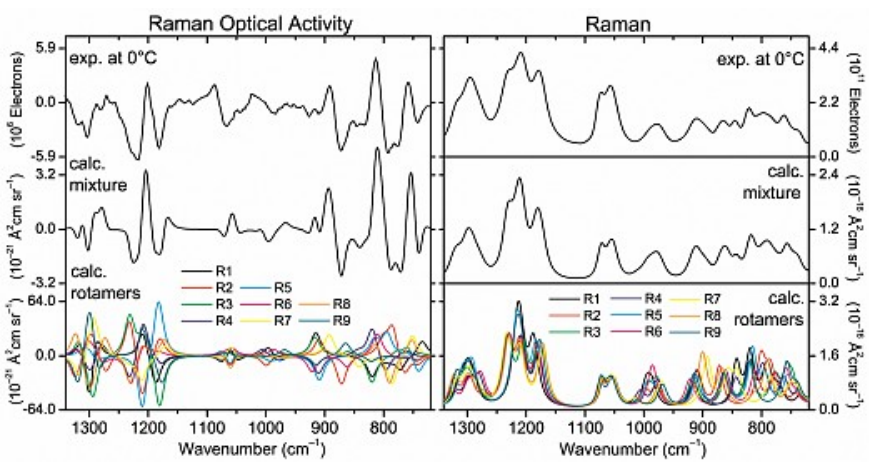

\section{Prediction of Perception: Probing the hOR17-4 Olfactory Receptor Model with Silicon Analogues of Bourgeonal and Lilial}

L. Doszczak, P. Kraft*, H.-P. Weber, R. Bertermann, A. Triller, H. Hatt*, and R. Tacke ${ }^{\star}$, Angew. Chem., Int. Ed. 2007, 46, 3367

Givaudan Schweiz AG, Dübendorf; Ruhr-Universität Bochum; Universität Würzburg

Due to the large number of human olfactory receptors and their complex activation patterns, the prediction of olfactory properties of new molecules still remains an important issue to address both from scientific and industrial points of view. In this article, to put the understanding of the odorant-receptor interactions to the test, silaanalogues (C/Si switch) of bourgeonal and lilial were synthesized and their odor properties assessed. Importantly, it was possible to predict the relative odor intensities of the sila-analogues quite accurately on the basis of their stereoelectronic properties alone from a computational homology model of the hOR17-4 receptor.

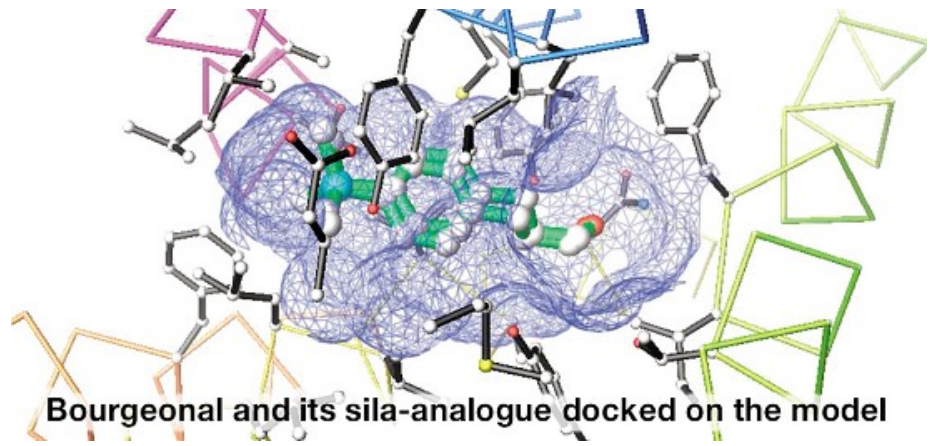

\section{Mechanistic Aspects of the Oxidative and Reductive Fragmentation of N-Nitrosoamines: A New Method for Generating Nitrenium Cations, Amide Anions, and Aminyl Radicals}

K. Piech, T. Bally*, A. Sikora, and A. Marcinek*, J. Am. Chem. Soc. 2007, 129, 3211

University of Fribourg; Technical University of Lodz, Poland

Nitric oxide has received enormous attention in the last few years due to its biological activity as a mediator in vascular muscle relaxation and a messenger in cellular signaling. In this article it is demonstrated that $\mathrm{N}$-nitrosoamines readily release $\mathrm{NO}$, not only upon photolysis, but also upon one-electron oxidation or reduction, thereby generating aminyl radicals, nitrenium cations or amide anions, respectively. These interesting reactive intermediates were fully characterized by their UV/Vis and IR spectra.

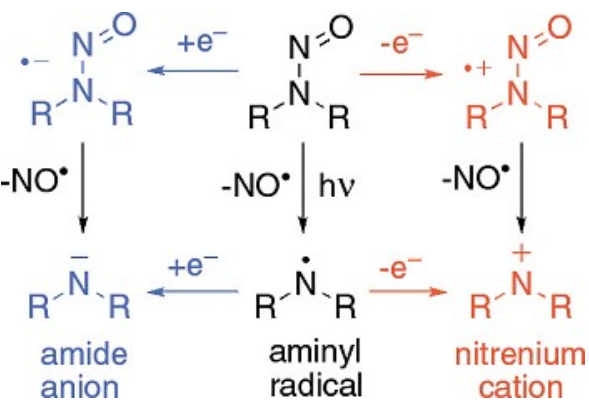

\section{Disruption of Amyloid-Derived Peptide Assemblies through the Controlled Induction of a $\beta$-Sheet to $\alpha$-Helix Transformation: Application of the Switch Concept}

R. Mimna, M. S. Camus, A. Schmid, G. Tuchscherer, H. A. Lashuel ${ }^{\star}$, and M. Mutter*, Angew. Chem., Int. Ed. 2007, 46, 2681

EPF Lausanne

In this article, the authors have demonstrated that a reversal of amyloid formation through a controlled induced transformation from $\beta$-sheet to soluble $\alpha$-helix structures can occur via the use of a peptidic switch element. They have shown that the induced structural changes in polypeptide regions that are not directly involved in amyloid formation can influence the stability and the dynamics of amyloid fibrils. Understanding the mechanisms of amyloid formation and clearance has important implications for the development of therapeutic strategies for the treatment of several amyloid diseases, including Alzheimer's and Parkinson's disease.
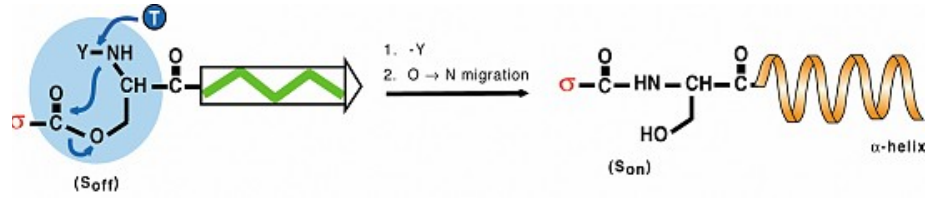